\title{
Tecnologias móveis no ambiente escolar: desafios e reflexões
}

\author{
Anne Alilma Silva Souza Ferrete ${ }^{1}$, Rodrigo Bozi Ferrete ${ }^{2}$, \\ ${ }^{1}$ Departameto de Educação -Programa de Pós-Graduação em Educação (PPGED) - \\ Universidade Federal de Sergipe (UFS) - São Cristóvão - SE - Brazil \\ ${ }^{2}$ Instituto Federal de Educação, Ciências e Tecnologia de Sergipe (IFS) - Aracaju - SE \\ - Brazil \\ alilma.ferrete50@gmail.com, rbferrete@gmail.com
}

\begin{abstract}
This study aimed to analyze and understand the teacher's reflections and the influence of the laptop in the classroom. The object of study focused on the statements of teachers with respect to use of laptop embedded in the elementary education, the College of Aplicação (CODAP). With this research we hope to contribute for the removal of information about the options for expanding the conditions for using the laptop as a practice to be adopted increasingly by teachers in public education institutions in order that teachers are responsible to train thoughtful being, reflective and critical. The results allow us to conclude that teachers must become aware of their training and pedagogical practice, and that their efforts are extremely important for student development.
\end{abstract}

Resumo. O presente estudo teve com o objetivo analisar e compreender as reflexões dos professores e a influência do laptop em sala de aula. O objeto de estudo centrou-se nos depoimentos dos professores com relação ao uso do laptop incorporado ao ensino básico fundamental do Colégio de Aplicação (CODAP). Com essa pesquisa espera-se contribuir para o levantamento das informações sobre possibilidades de ampliação das condições para o uso do laptop como prática a ser adotada cada vez mais pelos professores das instituições de ensino público, tendo em vista que os professores são encarregados de formar sujeitos pensantes, reflexivos e críticos. Os resultados obtidos permitem-nos concluir que os professores devem se conscientizar sobre sua formação e prática pedagógica, e que seus esforços são de extrema importância para o desenvolvimento do aluno.

\section{Introdução/ Justificativa}

O momento requer profunda revisão do sistema educativo. Os educadores têm como tarefa, a formação das novas gerações, e, ao mesmo tempo criar estruturas de capacitação e qualificação profissional, respeitando a sua natureza e tendo consciência de que suas necessidades estão mudando, e a escola precisa acompanhar a evolução.

Como bem enfatiza Almeida (1999), a inserção da tecnologia na escola, e mais especificamente, o uso da tecnologia computacional demanda certa mudança, quer no 
espaço físico da escola, quer na postura e atuação do professor no processo de ensino e de aprendizagem.

A atuação do professor no processo de ensino e aprendizagem requer dele uma formação continuada com foco nas práticas pedagógicas envolvendo o uso da tecnologia computacional, bem como uma reflexão sobre essas práticas na busca de detectar as dificuldades encontradas, e buscar soluções para que elas possam ser dirimidas.

Além da apropriação tecnológica necessária ao docente, o uso da tecnologia móvel em sala de aula poderá proporcionar a redução dos analfabetos tecnológicos, bem como do distanciamento proporcionado pela falta de domínio e uso destas tecnologias. Desta forma, com a chegada da tecnologia computacional e o uso de forma potencial como apoio pedagógico pelos professores. E é válido destacar que incluir digitalmente um indivíduo vai além de oferecer um ensino mediado pelo computador.

O professor ao utilizar a tecnologia móvel poderá proporcionar um ambiente educacional, e suscitar no aluno a problematização, a observação, o estímulo a uma visão crítica, viabilizar e ampliar a possibilidade de construção do conhecimento. Daí, ser necessário que o professor domine os recursos disponíveis pelas diversas tecnologias digitais para que possa estimular o aluno a buscar e construir seu conhecimento, desafiálo a (re)construir esse conhecimento e promover, desse modo, o pleno desenvolvimento da criatividade e autonomia desse ator social. Não precisa ter receio de que seu aluno saiba mais que ele. É evidente que esse aluno tem maior facilidade de manusear as tecnologias, visto que desde cedo está cercado por uma série de tecnologias. Então, é preciso que o docentes saiba usar o potencial tecnológico do aluno para apoiá-lo pedagogicamente em sala de aula.

Com estes pressupostos, o potencial pedagógico da tecnologia digital ganha dimensões diferentes. Sob esta visão, justificamos a introdução tecnologia móvel na Educação, com objetivos educacionais, tais como o incentivo à pesquisa, entre outros, que tanto os educadores gostariam de poder promover, estimulando maiores interesses aos alunos. Desta forma, na Educação o uso de objetos tecnológicos, cada vez mais modernos, assume outro papel, pois é através deste meio tecnológico que o aluno estará interligado aos conteúdos, ao professor e aos demais discentes quando necessário. A tecnologia, neste caso, torna-se uma ferramenta indispensável, uma vez que esta estará habilitada para suprir a ausência física entre o educador e do educando. (FERRETE, 2010).

De outra forma, a tecnologia móvel se mostra como elemento motor dos novos modos de produção, carecendo cada vez mais de indivíduos com formação profissional que lhe possibilite desenvolver conhecimentos teóricos, técnicos e operacionais voltados à produção de bens e serviços, além da exigência cada vez maior de formação em uso de tecnologias, que demonstrem qualidade e que sejam flexíveis, eficientes e eficazes no universo de campos de trabalho. Segundo Silva (apud CATTANI, 1997, p. 173) “[...] equipamentos informatizados de diferentes configurações têm sido introduzidos nos mais diferentes campos da atividade humana e não só na produção industrial".

A Informática tem tido grande importância devido a sua capacidade de transformação em todos os setores da vida, nas diversas áreas de trabalhos, como nas telecomunicações, na imprensa, na medicina, na segurança, no ensino etc., embora, 
existam grandes polêmicas quanto a possibilidade de "substituição" do homem pelo computador nos meios produtivos e de ensino e aprendizagem, devido ao grande contingente de excluídos desses processos.

Por outro lado, podemos evidenciar o pensamento de Oliveira (2007) quando acrescenta, que é fundamental a integração das tecnologias móveis em atividades de ensino, que professores e alunos desenvolvam trabalhos também não-disciplinares, entendendo o conhecimento de forma transversal, que sejam aproveitadas as imaginações dos alunos em suas produções e, por fim, que seja promotora de uma educação inclusiva.

Neste sentido, poderíamos pensar na necessidade de promover inclusão digital desses alunos, com a incorporação das tecnologias móveis no ensino público. Podemos verificar que é muito pouca a familiarização do pessoal com o emprego do computador como instrumento educacional, enquanto constatamos a boa vontade dos alunos em se fazerem presentes, motivados com a utilização da tecnologia computacional em sala de aula, como fonte de pesquisas na Internet ou até mesmo, para produzirem trabalhos com utilização dos diversos softwares, de acordo com as exigências de suas respectivas áreas.

Considerando que os processos de aprendizagem possam inserir indivíduos que compõem as novas gerações, no mundo da cultura e da sociedade, quando estes processos acenam para uma educação crítico-emancipatória, com uma linguagem voltada ao entendimento, capaz de garantir a esses indivíduos a formação de suas personalidades. Esse pensamento comunga com a assertiva de Boufleuer (1997, p. 69), que diz:

A educação, para obter um bom êxito no cumprimento de suas metas gerais de transmitir tradições culturais, de renovar solidariedades e de socializar as novas gerações, necessita ser concebida por seus agentes como uma ação comunicativa. A recorrência a uma linguagem voltada ao entendimento é, por assim dizer, a condição a priori, de possibilidade da própria experiência educativa.

Diante dessas considerações, faz-se necessário repensar sobre a abordagem dos conteúdos de ensino, bem como a sua prática. Isso poderá possibilitar que os indivíduos realizem seus planos, suas pesquisas em comum acordo, ou seja, entre professores, seus pares e a equipe de formação, de acordo com uma situação pré-definida e presente nas relações entre os indivíduos. Para tanto, segundo Oliveira (2004) é importante aproveitar a volatilidade, a interatividade e a flexibilidade das tecnologias digitais, potencializando práticas multiculturais, inclusivas, pensando no currículo escolar e integrando as ações e atividades escolares previstas integradas ao uso da tecnologia digital.

\section{Procedimentos metodológicos}

Acreditamos que definir o método seja primordial para o bom desenvolvimento de uma pesquisa, que tem seu êxito medido pela escolha e aplicação dos modelos mais adequados e que permitam o alcance pleno dos seus objetivos.

Desta forma, a natureza da pesquisa teve um caráter exploratório, de modo que permitiu uma visão mais precisa das reflexões dos educadores, tendo em vista as mudanças na cultura escolar, ocorridas diante da utilização da tecnologia móvel no cotidiano do Colégio de Aplicação da Universidade Federal de Sergipe, situado no município de São Cristóvão - SE. Fez-se necessário, portanto, delimitar primeiramente o 
nível de utilização do laptop dentro da Instituição, pois com a chegada das tecnologias móveis na rede pública, surgiu a necessidade de novos desafios com relação à formação de professores e gestores, para que o uso do laptop se efetivasse como apoio nas atividades pedagógicas, ou seja, a tecnologia realmente integrasse o currículo escolar, com objetivo de promover a cultura digital na instituição.

Ressaltamos a importância da observação do cotidiano escolar para validação dos dados coletado. Concluindo, o que esperamos é que, com os instrumentos anteriormente mencionados, tenhamos coletado dados não isolados, pois foi através destes que tivemos a possibilidade de visualizar a essência do problema a ser investigado.

\section{Experiências do cotidiano em sala de aula}

No tocante à formação dos educadores do Colégio de Aplicação (CODAP) houve participação dos gestores, e da coordenadora pedagógica, bem como de professores regentes. Desde o início essa participação demarcou uma capacitação de acordo com o pensamento de Almeida \& Prado (2009) que enfatizam uma formação que contemple os diferentes profissionais da gestão, em especial os gestores e coordenadores pedagógicos.

Neste sentido, pode-se dizer que a formação possibilitada pelo Projeto Um Computador por Aluno, oferecida pela equipe de formação da Universidade Federal de Sergipe (PROUCA/UFS) e destinada aos professores no Colégio de Aplicação, apresentou perspectivas de resultados significativos, pois seu corpo docente, bem como sua equipe diretiva, tiveram oportunidade de refletir sobre a prática pedagógica e reconstruí-la para torná-la mais efetiva.

Diante do exposto, ressaltamos que inicialmente a professora só utilizava o laptop nos dias de sexta-feira, e que a mesma estava no início da formação, participando da capacitação da segunda turma que foi realizada no período de agosto a dezembro de 2012, ou seja, realizamos a pesquisa paralelamente a formação da professora, e com uma turma do $6^{\circ}$ ano do ensino fundamental.

No decorrer do período observado, verificamos que estavam presentes em média vinte e cinco alunos, e no início da pesquisa observamos que os discentes se mostraram muito inquietos. Nesse sentido, apesar de a professora ter chamado atenção dos discentes e reconhecer o computador como uma forma de aprendizagem, no início da utilização dos laptops em sala, notamos que a mesma não conseguia atenção de todos os alunos. Diante do exposto, verificamos nas observações em sala de aula que a postura do professor pode influenciar na visão dos alunos no que diz respeito às potencialidades educacionais da tecnologia móvel. Conforme destaca Brito (2008):

Boa utilização do computador na escola pode propiciar a criatividade de novas formas de relação pedagógica, de novas formas de pensar o currículo e, portanto, pode também conduzir a mudanças no ambiente escolar; 2) o uso do computador na educação tem um potencial enorme, que não está diretamente relacionado à presença da máquina, mas sim do profissional, professor que firmou um compromisso com a pesquisa, com a elaboração própria, com o desenvolvimento da crítica e da criatividade, superando a cópia, o mero ensino e a mera aprendizagem (BRITO, 2008, p.112). 
Em contrapartida, algumas das observações feitas nos dias que se seguiram e em que o laptop foi utilizado nas atividades em sala de aula, permitiu constatar maior entusiasmo e participação dos alunos; além disso, foi observado diminuição no fluxo de dispersão dos alunos no momento de realização das atividades propostas. Nesse sentido, foi notória a ocorrência do ambiente colaborativo de aprendizagem entre os discentes, visto que faziam questão de repassar para os demais suas descobertas, além dos caminhos que as conduziam para a realização das atividades. Vale ressaltar que agiram de forma resoluta nas soluções dos diversos problemas.

Vale destacar ainda que a formação recebida contempla justamente a questão da contextualização, que possibilita ao professor reconstruir a sua própria prática pedagógica através da integração do computador com o currículo. Diante do exposto, antes de começar a tarefa proposta, a professora relembrava aos alunos que só era permitido "brincar" com o computador, depois de concluir as atividades. Durante esse intervalo de tempo, as atividades consistiam em pesquisas sobre um assunto do livro que foi pouco explanado, ou conteúdo que foi explorado durante a semana. Os alunos pesquisavam em vários sites sobre o tema, organizavam as ideias e colocavam no editor Kword em forma de texto e tópicos. Notamos que eles coletavam e anotavam as informações dos resultados que encontravam, e acrescentavam seu ponto de vista. Mas, conforme Bezerra, Romeiro e Rodrigues (2004), esta pesquisa pode ser feita de duas formas: livre ou direcionada.

Aproximando a realidade encontrada no CODAP, em relação à pesquisa livre, a docente "[...] orientava os alunos a seguirem os lugares virtuais que eles desconheciam, permitindo-lhes vislumbrar imagens criativas, assuntos diversos e situações inusitadas como o descobrimento de ideias antes desconhecidas" (ibidem, p.88). No entanto, apesar de ser nomeada de "pesquisa livre", estas sempre tinham objetivos claros, para que o aluno não procurasse fontes sem objetividade, e não se limitasse somente a buscar e aproveitar o primeiro endereço ou assunto pesquisado na internet.

No que diz respeito à pesquisa direcionada, esta, como o próprio nome já diz, "[...] teve o objetivo mais restrito, pois requereu do aluno seleção de sites destinados ao conteúdo proposto, evitando assim dispersão e relaxamento quanto à proposta da professora no horário da aula" (ibidem, p.88). Neste sentido, diante das observações foi notório que na maior parte das aulas ministradas pela professora, a metodologia utilizada para pesquisa era de forma direcionada, uma vez que ela explicava qual era o tema, o que queria, e orientava os alunos pedindo que eles buscassem informações através do Google. O entusiasmo, curiosidade e autonomia, foram verificados nos acessos aos sites a serem explorados que continham objetos virtuais de aprendizagem (OVA), principalmente relacionados ao assunto transmitidos pela docente. Uma preocupação constante da professora, com relação ao uso da internet no processo de ensino, estar vigilante e encaminhar os alunos a lerem as informações e produzirem o próprio conhecimento.

Vale mencionar que após realização das oficinas oferecidas nas capacitações promovidas pela equipe de formação do PROUCA/UFS, os docentes passaram a realizar pesquisas nos sites dos objetos virtuais de aprendizagem (OVA). Neste sentido, a docente utilizava alguns objetos virtuais disponíveis em alguns sites que continham os objetos de aprendizagem, modificando consideravelmente sua metodologia, pois 
acessavam documentários, vídeos, jogos e atividades de forma complementar/revisar o conteúdo passado para o aluno, e os discentes realizavam pesquisas e atividades nesses sites. Conforme avançavam nos módulos do curso de formação continuada, os docentes passavam a produzir e utilizar seu próprio objeto virtual de aprendizagem, melhorando consideravelmente o planejamento de suas aulas e a assimilação do conteúdo por parte dos discentes.

Outro ponto importante a ser evidenciado em relação ao papel do professor frente a essa tecnologia em sala de aula, visto que, com a inserção da tecnologia computacional, conforme Mercado (2002, p.138), “[...] perde o posto de dono do saber, mas ganha uma nova e importante função, o de mediador da aprendizagem". A partir da consciência dessa função, houve possibilidade do aluno passar a ser responsável pela sua própria aprendizagem, e ter participação ativa desse processo.

Nesta perspectiva, observamos que a professora se aproximou do papel de mediadora da aprendizagem. Isso foi notado, quando a mesma ao orientar os alunos na realização da pesquisa, questionava algumas situações, a fim de provocar no aluno reflexão sobre o tema. Conforme Moran (2000 p.44), “o computador nos permite pesquisar, simular situações, testar conhecimentos específicos, descobrir novos conceitos, lugares, ideias. Produzir novos textos, avaliações, experiências". Nesta situação, a professora fez o papel de mediadora do processo de ensino e de aprendizagem, permitindo que o aluno tivesse autonomia ao buscar informações para construir o conhecimento. E em seguida, questionou os alunos sobre o que eles tinham encontrado, a fim de socializar os dados coletados, e colocando-os na lousa. A partir desta atitude de socialização, foi possível perceber uma diversidade de informações encontradas pelos alunos, como por exemplo: significado do tema, manifestações locais, comidas específicas. Apareceram também dados semelhantes que não foram anulados, e sim utilizados para complementação das informações encontradas. Essa dinâmica permitiu que a professora não fosse a principal detentora do saber, pois, a partir do seu acompanhamento, estímulo e orientação, os alunos puderam ter acesso às informações e exercitar a capacidade de extrair pontos que, para eles, eram importantes. Neste sentido, conforme Moran (2000, p. 138), a professora "[...] passa a dirigir as pesquisas dos alunos, apontar caminhos, esclarecer dúvidas, propor projetos e, sem dúvida aprender muito mais".

No decorrer das aulas, percebemos que, de forma espontânea, cada aluno pesquisava o que mais lhe chamava a atenção, e como forma de lembrar o que encontrou, copiava no caderno pontos e sites interessantes. Um aluno preferia não copiar no caderno, selecionava o texto e salvava no KWord, diretamente e como a maioria da turma não sabia deste procedimento, ele se prontificou explicar para os colegas como fazer. O aluno foi para lousa e explicou aos demais como proceder.

Segundo relato da professora, e durante as observações, percebemos fluir um ambiente colaborativo de aprendizagem. Com o uso da tecnologia computacional, os alunos passaram a interagir mais, através da troca dos laptops; bem como na ajuda, na ornamentação do trabalho, na procura de informações pela internet, como também no manuseio do computador. Um fato interessante foi de um aluno que, conforme a professora apresentava dificuldade na interpretação dos textos e se recusava, muitas vezes, a lê-los. Diante da realidade vivenciada, a professora passou a solicitar que ele 
fizesse a leitura dos dados pesquisados e, desta forma, o aluno lia mesmo sem perceber, sem ver aquilo como obrigação, e contanto com a participação dos demais discentes com suas contribuições. Neste sentido, paulatinamente isso deixou de ser um problema para o aluno. A estratégia, segundo Cagliari (1998), foi de trabalhar em sala de aula a leitura de maneira prazerosa sem que esse processo se tornasse árduo e chato.

Observamos que a professora atribuía notas em todas as pesquisas realizadas e permitia que os alunos brincassem ao término das atividades. Este tipo de comportamento pode restringir a avaliação ao ato de aplicar prova e atribuir nota, mas ela perpassa pelos métodos quantitativos e qualitativos de aprendizagem, além de ser uma avaliação processual. Isso porque a função da mesma era desenvolver no aluno o seu aspecto intelectual, social e moral; e a docente precisa planejar seu ensino para alcançar esse objetivo (LUCKESI, 1998).

Por outro lado, percebemos que limitar a utilização da tecnologia computacional somente como fonte de pesquisa, não seria suficiente, pois no dia em que não fosse possível acessar a internet, a aula seria cancelada? Primordialmente, esclarecemos que a docente precisaria ter em mente sobre a importância do uso da tecnologia em sala de aula e utilizá-la potencialmente. Conforme Valente (1999, p.84):

\begin{abstract}
O professor necessita ser formado [...] e deixar de ser o "entregador" da informação para o aprendiz. Isso significa ser formado tanto no aspecto computacional, de domínio do computador e dos diferentes softwares, quanto no aspecto da integração do computador nas atividades curriculares. O professor deve ter muito claro quando e como usar o computador como ferramenta para estimular a aprendizagem. Esse conhecimento também deve ser construído pelo professor e acontece na medida em que ele usa o computador com seus alunos e tem o suporte de uma equipe que fornece os conhecimentos necessários para o professor ser mais efetivo nesse novo papel.
\end{abstract}

Corroborando com o autor, o professor pode criar um ambiente de aprendizagem com o uso de outros recursos que esta tecnologia oferece. Porém, uma boa parte dos professores não tem apropriação tecnológica suficiente na área da informática; e por conta desse desconhecimento, preferem usar o equipamento somente para pesquisas.

Com isso, intuímos também que, como a maioria dos docentes, aquela professora não possuía conhecimentos suficientes dos recursos do laptop, nem dos softwares disponíveis, principalmente no início de nossa pesquisa. Isto pode ser decorrente da falta de assiduidade nas formações que a equipe de formação da Universidade Federal de Sergipe/UFS oferecia aos professores das escolas que foram contempladas com o projeto UCA. Apesar de que o fato não se limita somente à falta de conhecimento na área de informática, pois, outro ponto a ser considerado, é o fato de não saber como utilizar o computador em sala de aula como apoio pedagógico.

Diante do que foi exposto, podemos concluir que a inserção do computador em sala de aula pode colaborar para um processo de ensino e de aprendizagem mais dinâmico, que estimule o surgimento de indivíduos autônomos na construção do saber. 
Todavia, faz-se necessário que a docente planeje atividades diversificadas, pensando em obter resultados significativos. Todavia, foram detectadas também potencialidades do desenvolvimento do trabalho pedagógico utilizando o laptop.

De acordo com esta fala e as observações registradas, constatamos que o uso do computador na escola pode promover, primeiramente, a inclusão digital, pois muitos alunos não têm acesso à internet em casa devido à condição social. Porém, essa inclusão não deve ficar somente no âmbito técnico do equipamento, mas também em permitir que os alunos sejam autônomos, críticos e criativos para atuarem na sociedade (MERCADO, 2006). Para que isso aconteça, "é primordial que os educadores se apropriem de tais tecnologias, a fim de proporcionarem ambientes favoráveis ao crescimento e à construção conjunta de conhecimento" (TEIXEIRA, 2004, p.103).

Portanto, notamos que existem obstáculos e potencialidades ao se trabalhar com o laptop em sala de aula, mas cabe ao docente mediar o processo de ensino, pois o computador sozinho não passa de uma máquina. E para Kenski (2007, p.121), “os processos de interação e comunicação no ensino sempre dependeram muito mais das pessoas envolvidas no processo do que das tecnologias utilizadas, seja o livro, o giz, ou o computador e as redes". Com isso, somente a presença da tecnologia computacional em sala de aula não assegura que este irá contribuir para o processo de ensino e de aprendizagem, pois resultados satisfatórios dependem de outros fatores. Um deles é o reconhecimento por parte dos professores de que esta ferramenta pode servir como apoio pedagógico em suas aulas. Entretanto, é possível notar uma resistência por parte desses profissionais ao trabalhar com essa tecnologia, devido à falta de apropriação tecnológica.

\section{Considerações finais}

Este artigo teve como objetivo analisar o uso do laptop do Projeto Um Computador por Aluno (UCA) no processo de ensino com a turma do $6^{\circ}$ Ano do Colégio de Aplicação (CODAP/UFS). Através de um estudo de caso, observamos a forma como a docente da turma utilizava o computador em sua prática pedagógica.

A aplicação das entrevistas foi de vital importância para que pudéssemos ter uma visão ampla do ponto de vista desses educadores, seus anseios, preocupações, consciência e dificuldades encontradas em relação à utilização desse recurso tecnológico. E em nossa pesquisa, registramos, então, que a visão dos professores, com relação ao uso da tecnologia computacional em sala de aula, não se reveste de características especiais, porém, considera como um potencial pedagógico a ser assimilado e aproveitado para melhoria do ensino. Assim, percebemos que a professora que participou efetivamente da pesquisa, reconhece a importância e a necessidade de profundas reflexões sobre a realidade e suas práticas, em relação ao que os demais educadores da escola vivenciam atualmente.

Constatamos que os alunos, mostraram-se plenamente receptivos ao uso da tecnologia e levantamos a hipótese de que os conteúdos reforçados com o uso do laptop foram mais bem assimilados. Constatamos também que a utilização da tecnologia digital de informação e comunicação promoveu maior interação entre os alunos da turma, e entre a professora e os alunos, visto que eles se ajudaram tanto na busca de informações, 
como na apropriação tecnológica. Isto foi observado em todas as atividades que tinham como apoio pedagógico o uso do laptop.

No que diz respeito às potencialidades, observamos que a inserção do computador possibilitou a inclusão digital dos alunos, pois muitos deles não tinham acesso a essa tecnologia no seu cotidiano, nem em suas residências. Como também, a aquisição do conhecimento com o uso da tecnologia móvel passou a se dá de forma mais dinâmica e mais autônoma.

Diante do que foi exposto, há necessidade de que a escola tome como prática, o estabelecimento de espaços para reflexão e avaliação sobre a educação e tecnologia, visando uma melhoria continuada dos seus processos educativos, o que poderá contribuir muito para sua promoção.

Desta forma, podemos sugerir, primeiramente, que a escola proporcione mais cursos de capacitação de forma contínua e presencialmente para os professores, e contribuam para utilização dos recursos tecnológicos com o uso de softwares educativos, demonstrando a utilidade do computador como uma ferramenta que servirá como apoio pedagógico. Conforme descrito anteriormente, esta tecnologia inserida no processo de ensino e aprendizagem, bem como a possibilidade de se montar grupos de estudos para a troca de experiências, assessoramento e suporte em relação à incorporação e utilização das tecnologias educacionais, conforme preocupação já evidenciada nessa pesquisa. Há necessidade de que a escola ofereça também condições de trabalho e manutenção periódica dos equipamentos, das instalações elétricas, melhoria do acesso a internet, bem como obtenção e atualização dos softwares periodicamente.

\section{References}

Almeida. Maria Elizabeth B. de. (1999) "Ensinar e aprender com o computador: Articulação inter-trans-disciplinar”, Boletim Salto para o Futuro, Brasília. Informática na educação.

Almeida, Maria E. B. de and PRADO, Maria E. B. B. (2009) Formação de educadores para o uso dos computadores portáteis: indicadores de mudança na prática e no currículo. In: Conferência Internacional de Tecnologias de Informação e Comunicação na Educação, 6, Braga, 2009. “Anais ...” Braga, Portugal: Universidade do Minho.

Bezerra, Aline Vieira; ROMEIRO, Iara Maria Moreira; RODRIGUES, Jonália Costa. A internet no ensino de línguas estrangeiras. In: MERCADO, Luís Paulo Leopoldo (orgs.). "Tendências na utilização das tecnologias e comunicação na educação". Maceió: EDUFAL, 2004.

Boufleuer, José P. (1997) "Pedagogia da ação comunicativa: uma leitura de Habermas". Ijuí, Ed. UNIJUÍ. (Coleção Educação).

Brito, Glaucia da Silva. "Educação e novas tecnologias: um re-pensar". 2.ed. Ibpex, 2008 .

Cagliari, Luis Carlos. "Alfabetização sem bá-bé-bi-bó-bú”. 10 ed. São Paulo: Scipione, 1998. 
Glaucia da Silva. Educação e novas tecnologias: um re-pensar. 2.ed. Ibpex, 2008.

Cattani, A. D. et al. (1997) “Trabalho e Tecnologia, Dicionário Crítico”, Petrópolis: Vozes.

Chizzotti, A. "Pesquisas em Ciências Humanas e Sociais", São Paulo: Cortez, s.d.

Ferrete, Anne Alilma S. Souza. (2007) Sala de aula virtual: análise de um espaço vivido na EAD. In: França, Lilian C. Monteiro.; Ferrete; Anne Alilma. S. Souza.; Gouy, Guilherme B. (Orgs.). "Educação a Distância: ambientes virtuais, TIC e Universidades Abertas". Aracaju: Criação, 2010.

Kenski, Vani Moreira. "Educação e tecnologia: o novo ritmo da informação". Campinas, SP: Papirus, 2007.

Luckesi, C. Carlos. “Avaliação da aprendizagem escolar”. 11. ed. São Paulo: Cortez, 1998.

Mercado, Luís Paulo Leopoldo. "Novas tecnologias na educação: reflexão sobre a prática”. Maceió: EDUFAL, 2002.

Mercado, Luís Paulo Leopoldo. "Experiências com tecnologias de informação e comunicação na educação”. Maceió: EDUFAL, 2006

Moran, José Manuel. Ensino e aprendizagem inovadores com tecnologias audiovisuais e telemáticas. In: MORAN, José Manuel. (Orgs). "Novas tecnologias e mediação pedagógica". Campinas: Papirus, 2000. (p.11-65)

Oliveira, J. M. A. (2004) "O hipertexto como imaginação do currículo e de conhecimentos produzidos na escola", Ano 2 - Voll.

Teixeira, Adriano Canabarro. "Inclusão Digital: novas perspectivas para a informática educativa”. Ijuí: Ed. Unijuí, 2010.

Valente, J. A.; MAZZONE, J. S.and BARANAUSKAS, M. C. C. A. (2007) "Aprendizagem na Era das Tecnologias Digitais: Conhecimento, trabalho na empresa e design de sistemas", São Paulo, Cortez Editora, v. 1. 271 p.

Valente, J. A.(Org.). (2003) "Formação de educadores para o uso da informática na escola”. Campinas, SP, UNICAMP/NIED. 